\title{
DRIVING IN EMERGENCIES WITH USE OF SYSTEM OF THE HELP TO THE DRIVER
}

\author{
Vasyugova S.A., Nikolaev A.B.
}

The purpose of this article consists in research of modern technologies in automotive industry by the analysis and carrying out technical experiment. The main attention concentrates on traffic safety, which is carried out by automation and modernization of vehicles. In article innovative solutions on implementation of the safe movement of the car are considered. The system of the help to the driver in emergencies of "System help" is offered. This system is intended for implementation of automation of certain processes of the car at those moments of the movement when the driver ignores or doesn't notice the informing signals of system.

Keywords: automation; transport; car; "System help"; controller; sensor; iSys.

\section{Introduction}

Safety on roads is a priority question around the world today. With development of infrastructure the transport system of the countries develops [1]. People became more dependent on transport and in this regard, on roads the number of cars, motorcycles, a special-purpose equipment and other transport has sharply increased [1-16]. It is one of factors which have served to increase in number of road accident on roads [2, 3].

The modern automotive industry is directed, first of all, to achievement of the maximum safety of the car, and his comfortable use [4, 5]. Vehicles are modernized and improved. Requirements for safety and comfort of equipment constantly become tougher, forcing producers to invent new systems and to introduce new technologies [6-8]. 


\section{Innovative solutions in safety of the car}

Traffic safety directly depends on quantity and quality of transport structure on roads. Every year the number of cars accelerated continues to increase the quantitative presence on roads of the different countries of the world [1-16].

Today it is necessary to improve as much as possible ways of the organization of traffic by development and deployment of the automated systems and devices $[9,10]$. It is necessary to provide with information and technical support of drivers and other participants of the movement. It will allow to reduce the number of road accident that will also affect load of highways [11, 12].

Developers of cars have already made huge break in automotive industry, having created a number of auxiliary devices (sensors, a radar, chambers, etc.), and also, the automated systems [13].

Modern cars have begun to equip with system of recognition of road signs [14]. This system is intended to distinguish road signs of restriction of speed and to inform the driver on the high-speed mode on a passed site of the road. The notification of the driver happens in several ways [15]:

- the sound notification and emergence of the informing badge on the dashboard screen;

- the sound notification and projection of the informing badge on a car windshield.

System of recognition of road signs (Traffic Sign Recognition, TSR) many known car makers - Audi have in the asset, BMW, Ford, Mercedes-Benz, Opel, Volkswagen. The system of recognition of road signs on Opel cars is a part of the Opel Eye system. The Opel Eye system is noted among the best developments in the field of automobile safety of 2010. Mercedes-Benz called the Speed Limit Assist system (the monitoring system of restriction of speed), Volvo - Road Sigh Information, RSI (system of informing on road signs) [16].

This system is capable to reduce the number of road accident on roads and to increase the level of traffic safety. Besides system of rec- 
ognition of road signs, the system of recognition of pedestrians began to take root widely.

The system of recognition of pedestrians is intended for identification of objects around the car and prevention of collision with them. This system as the main technical knots, as a rule, includes chambers and a radar (motion sensors). Technical knots of the car scan space on perimeter, collect information and issue it on the main controller (on-board computer). At detection of the pedestrian video cameras and additional confirmation by sensors, the system calculates probability of collision, proceeding from remoteness of object and speed of the movement of both (or more) objects and, in case of probable collision, gives the warning signal accompanied with sound on the panel screen. If after signals of system the vehicle doesn't change the movement, then the system independently reduces speed of the car and stops him completely.

For the first time the system of detection of pedestrians has been used on Volvo cars in 2010. Now the system has a number of modifications:

- Pedestrian Detection System from Volvo;

- Advanced Pedestrian Detection System from TRW;

- EyeSight from Subaru.

Also, today one of actively developing directions focused on increase of safety of processes of traffic is development and deployment of system of communication between cars. This system represents a kind of a wireless network (WLAN, Wireless Local Area Network) in which two types of knots - the vehicle (the car, the motorcycle) and infrastructure facilities (the traffic light, the center of regulation of the movement) are allocated [7]. The system of communication between cars is a component of the intellectual transport system (ITS).

The system of communication between cars is intended for the safe movement of all participants on the road. Work of system consists in an exchange of technical information between vehicles. Use of this system is necessary at journey of unregulated intersections, the com- 
plicated travel, turn on the left, about rear collision and other dangerous situations.

All above described developments in the field of automation have undergone a number of testings and are actively operated. Improvement and modernization of such systems proves that they are very effective and necessary for modern transport system.

It is very important to develop internal system of the help to drivers. The car equipped with internal system of the help is capable to provide the safe movement on roads, and also, is capable to help the driver in difficult and emergencies.

\section{System of the help to the driver in emergencies}

It is very important to create system which is capable to analyze independently road process and to control actions of the car. However after the detailed analysis of work of auxiliary systems of the car, a conclusion has followed that traffic safety is carried out not fully, and process of use of the vehicle can be improved. For achievement of this purpose a number of researches and testings on improvement of quality of work of the car and increase in traffic safety has been carried out.

In article the new system of the help to the driver in emergencies of "System Help" which is capable to automate work of the car is offered, having increased thereby the level of safety of process of traffic $[5,6]$.

Work of this system consists in an assessment of the surrounding situation by collection of information arriving from external sensors on the on-board computer of the vehicle and decision-making on impact on the hardware executive mechanisms, and also, to informing all active participants of traffic. Active participants of the movement are understood as those vehicles with which physical contact (collision, a contact etc.) is possible, it is represented in figure 1 (fig. 1).

The system makes the decision, analyzing all arriving data. Therefore, influences as the hardware executive mechanisms, on which she is established and on the hardware executive mechanisms of active 
participants (provided that all the hardware are equipped with this system), if it is necessary.

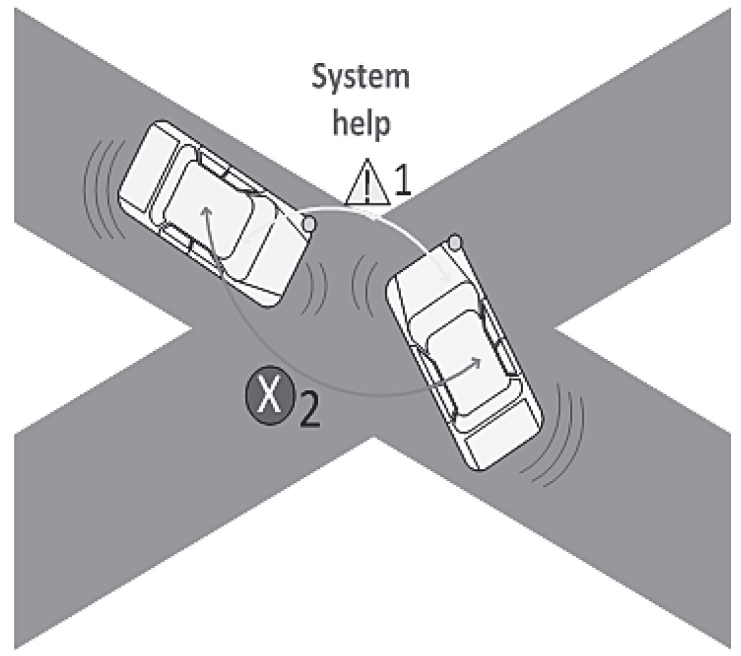

Fig. 1. An example of interaction of two cars

( 1 - exchange of the informing signals of danger; 2 - giving of the operating signals)

The principle of interaction and control of environmental conditions by system in borders of one object (car) represents process of collection of information from the external equipment and data transmission on the main computer (controller), it is represented in figure 2 (fig. 2).

The System help system includes an automobile radar, the iSys module, a video camera, WLAN-the module and the on-board computer, which interact on one or several CAN-to tires. The automobile radar is a sensor, which uses radio waves for detection of objects around the car. Video cameras allow receiving images of a surrounding situation of the car, which are processed by system. On the basis of the analysis of the arriving signals from the radar and a video camera the complex assessment of potential danger of objects by results of which the system notifies the driver is made and if it is necessary, influences the hardware executive mechanisms. By means of module 
WLAN-the system has an opportunity also to inform and influence executive mechanisms of the active hardware.

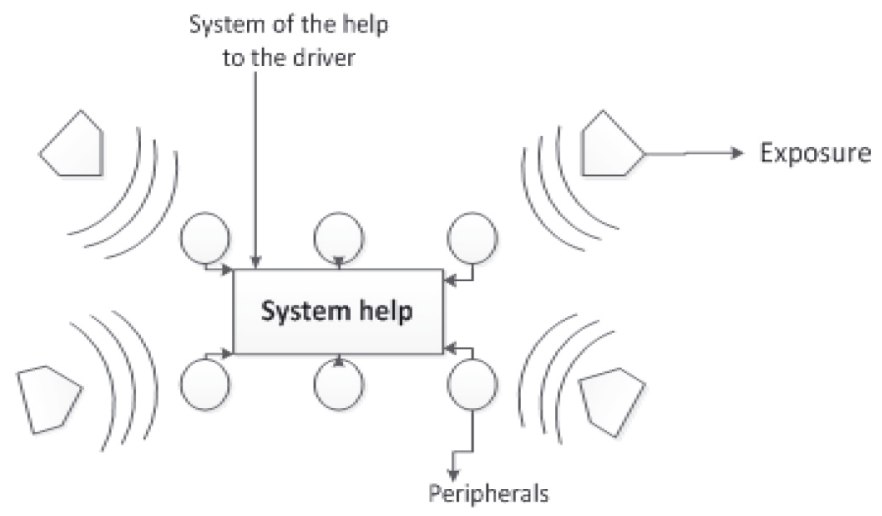

Fig. 2. The principle of interaction of system with external conditions

The arrangement of working knots can differ depending on the internal device of the car. The control unit performs the main work. This block is the on-board computer. The on-board computer interrogates the sensors and sensors established in different parts of the car, then processes collected information and gives the operating signals on devices of the car, and the informing signals on the driver's monitor. In addition, he processes entering external (from a network) signals and will transform them to the operating output signals, which, in turn, are broadcast on the automobile audio system and the information display. In emergency, the system of communication can influence governing bodies of the car, preventing accident [2].

\section{Structure of the "System help"}

The system of the help to the driver is complex and includes, besides specialized software, the external and internal equipment, it is represented in figure 3 (fig. 3). In drawing, the following knots of system are presented: 
Cam - Surveillance camera.

Sens - motion sensors (radar).

Bcom - on-board computer. Is the controller, which collects, analyzes, will transform information to the operating signals. Under certain conditions, the on-board computer carries out functions of informing and the prevention of the driver and if the driver ignores the arriving signals of system, the computer assumes management of behavior of the car.

iSys - the module connected to CAN-to the tire and which is reading out necessary information from the digital tire. At an emergency, the module receives a special signal then it sends the digital program to executive mechanisms that leads to shutdown of work of one or several conditions for operation of the engine.

MOD - WLAN-the module and DSRC-the module, which provide wireless access to system of the car and communication in short, distances.

Connection of this system process individual for each installation. He depends on a complete set and technical characteristics of the car.

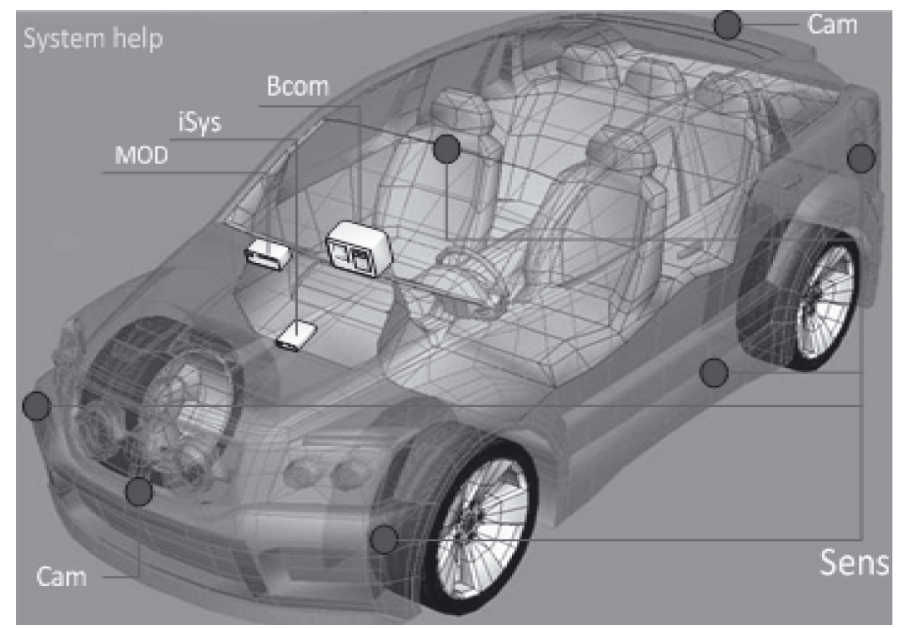

Fig. 3. The main components of the system 
All sensors, chambers, executive mechanisms, the on-board computer, modules and other devices are connected to digital CAN-to the tire. This tire allows connecting among themselves a large number of knots. In addition, her feature is that it represents twisted couple that allows avoiding a large number of additional conducting and excess knots. Thanks to this tire, it is not necessary to organize transfer of the first unit of information from knot to knot on a separate wire. Such tires already exist almost in all modern cars that will make process of installation of the System help system fast and reliable.

The scheme of work of system is submitted in the following drawing and it is represented in figure 4 (fig. 4).

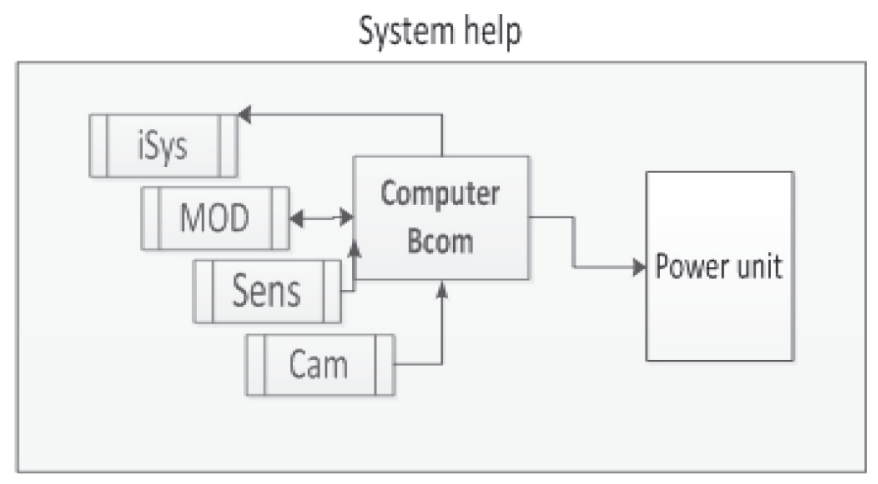

Fig. 4. The scheme of work of the system

The system performs operations on exchange of information between the working knots, collects data, processes and forms the operating signals.

The system of the help to the driver in emergencies of "System help" in the future can become an important component of the car. She is capable to analyze a surrounding situation on the road and to control behavior of the car if necessary.

Very important feature of system is ability of communication between systems that allows to increase overall performance of system and traffic safety. 
It is supposed that such system will be useful at journey of difficult sites of the road, to the movement of the car under difficult weather conditions, journey of unregulated intersections and at others potentially emergencies.

\section{Carrying out experiment on robotic platforms}

In experiment, the following robotic devices are used: a driving platform based on the EV3 controller, a driving platform based on the NXT controller with use of additional Wi-Fi - the HumaRobotics block. Also in experiment the non-automatic model of the car and the card of a marking of the road district are used. Programming of driving platforms is carried out with use of the LEGO MINDSTORMS EV3 EDUCATION software product.

Robots are developed based on the design LEGO MINDSTORMS complex. Robots are also equipped with ultrasonic sensors, which can measure distance to objects. The ultrasonic sensor functions by distribution of sound waves and measurement of time, which is required in order that the reflected wave has returned to the sensor. The sensor is connected to the controller by means of a cable, which is connected to port of input on the controller and will play a role of an automobile radar.

The controller of the robot plays a role of the on-board computer of the car, which is connected to external and internal sensors (in our case it is the ultrasonic sensor). The ultrasonic sensor will measure distances to objects during the movement then it will send information to the controller. The purpose of experiment consists in determination of quality of work of system at interaction of two objects at which both objects are equipped with the System help system.

The number of attempts -3 . Speed of the movement of each robot: $30,60,90$ turns of the main motors a second. Speed of the movement of not automated car is absent.

Chronology of experiment: three objects approach the unregulated intersection; on incorrect assessment of the situation at the intersection, two objects begin (robots A and B) his journey in this connection, 
the trajectory of their movement will be crossed in the center of the intersection and will lead to collision, it is represented in figure 5 (fig. 5).

As estimated criterion of overall performance of system data on final distance from the case of one robot to another after right operation of system are taken. Results of experiment are given in the table (Table 1).

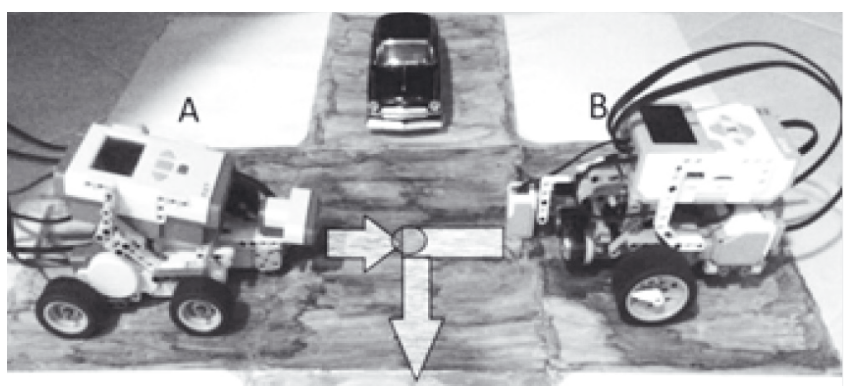

Fig. 5. Experiment

Table 1.

Results of experiment

\begin{tabular}{|c|c|c|}
\hline Number of attempt (No.) & Collision & Distance $(\mathrm{cm})$ \\
\hline 1 & no & 7 \\
\hline 2 & no & 7 \\
\hline 3 & no & 6 \\
\hline
\end{tabular}

\section{Conclusions}

Automation of processes of the car is necessary and important area in automotive industry. With modernization of this area, safety of movement directly depends.

The System help system is capable to provide comfortable and safe use of the car, and to help the driver with difficult and dangerous situations on roads. 


\section{References}

1. Internet resource: http://www.gibdd.ru/

2. Vasyugova S.A., Nikolaev A.B. Analysis and research of opportunities of system of the help to the driver of "SYSTEM HELP". In the world of discoveries. Collection "Natural and Technical Science", No. 4 (64). Scientific and Innovative Center publishing house, Krasnoyarsk, 2015. The magazine is included in the List of VAK of the leading reviewed scientific magazines.

3. Isaev I.A. Receiving, transformation, analysis of information on the mass of moving heavy-load road vehicles. Young scientist. 2015. No. 9, pp. 1489-1495.

4. Internet resource: http://systemsauto.ru/

5. Vasyugova S.A., Nikolaev A.B. Analysis and research of opportunities of system of the help to the driver of "SYSTEM HELP". In the world of discoveries. Collection "Natural and Technical Science", No. 4 (64). Scientific and Innovative Center publishing house, Krasnoyarsk, 2015.

6. Vasyugova S.A., Nikolaev A.B. Analysis of work of system of the help to the driver. Questions of modern technical science: new view and new decisions. The collection of scientific works following the results of the international scientific practical conference, No. 2. Yekaterinburg, 2015.

7. Autosar: Automotive open system architecture. http://www. autosar.org/.

8. CAMP Vehicle Safety Communications Consortium. Vehicle safety communications project task 3 final report, Mar. 2005. Online: http:// www.intellidriveusa.org/documents/ vehicle-safety.pdf

9. United States Congress House. Committee on Transportation, \& Infrastructure. Subcommittee on Highways and Transit. How Autonomous Vehicles Will Shape the Future of Surface Transportation: Testimony of the Honorable Kirk Steudle, Director, Michigan Department of Transportation, House of Representatives, One Hundred Thirteenth Congress, first session, November 19, 2013.

10. Martelle S. "Self-driving Cars and the Liability Issues They Raise." Project Consumer Justice. May 2012. Online. http://www.protectconsumerjustice.org/self-driving-cars-and-the-liability-issuesthey-raise.html. 
11. Simpson J.M. "DMV's Autonomous Vehicle Regulations Must Protect Users' Privacy." Consumer Watchdog. March 2014. Online. http://www.consumerwatchdog.org/resources/dmvtestimoIndustry Shift Applied Innovation Review 22 Issue 1 June 2015 ny031114.pdf.

12. Mui C. "Will Auto Insurers Survive their Collision with Driverless Cars?” Forbes. March 2013. Online. http://www.forbes.com/sites/chunkamui/2013/03/28/will-auto-insurers-survive-their-collisionwith-driverless-cars-part-6/

13. Boulton Clint. "Nissan Lays Out Roadmap for Autonomous Cars." The Wall Street Journal Blog. July 2014. Online. http://blogs.wsj. com/cio/2014/07/17/nissan-lays-out-road-map-for-autonomouscars/

14. Weiss C.C. "Toyota Details Its Automated Highway Driving System." Gizmag. October 2013. Online. http://www.gizmag.com/toyota-automated-highway-driving/29378/

15. Automated Vechile Institute. 2014. Online. http://www.usfav.com/ currentAV.html

16. Silberg Gary. Self-Driving Cars: Are We Ready? KPMG. October 2013.

\section{DATA ABOUT THE AUTHORS}

Vasyugova Svetlana Alekseevna, Graduate Student of Automated Control Systems Chair

State Technical University - MADI

64, Leningradsky prospekt, Moscow, 125319, Russian Federation vas715@gmail.com

Nikolaev Andrey Borisovich, Laureate of the Government Prize of the Russian Federation, Honored Worker of Science of the Russian Federation, Dr.Sci.Tech., Professor, Head of the Department State Technical University - MADI 64, Leningradsky prospekt, Moscow, 125319, Russian Federation nikolaev.madi@mail.ru 